\title{
HPTLC Fingerprint Profile (Phenolics) of Selected Cyathea Species from Western Ghats, South India
}

\author{
Janakiraman Narayanan and Johnson Marimuthu alias Antonysamy \\ Centre for Plant Biotechnology, Department of Botany, St. Xavier's College (Autonomous), Palayamkottai, Tamil Nadu 627 002, India \\ Correspondence should be addressed to Johnson Marimuthu alias Antonysamy; ptcjohnson@gmail.com
}

Received 25 August 2015; Revised 2 January 2016; Accepted 4 January 2016

Academic Editor: Vivian Y. Shin

Copyright (C) 2016 J. Narayanan and J. Marimuthu alias Antonysamy. This is an open access article distributed under the Creative Commons Attribution License, which permits unrestricted use, distribution, and reproduction in any medium, provided the original work is properly cited.

\begin{abstract}
HPTLC analysis was performed to study the phenolics, flavonoids, and tannins profile of Cyathea nilgirensis Holttum, Cyathea gigantea (Wall. ex. Hook.) Holttum, and Cyathea crinita (Hook.) Copel. The maximum number of bands was observed in the ethanolic extracts of $C$. crinita. The phenolic bands with $R_{f}$ values $0.05,0.32,0.43,0.75$ (quercetin), and 0.83 demonstrated their occurrence in all the three studied species of Cyathea. Flavonoids with $R_{f}$ values $0.05,0.23,0.30,0.43$, and 0.73 showed their presence in the three studied species of Cyathea. Tannins with the $R_{f}$ values $0.05,0.09$, and 0.82 determined their existence in all the three studied Cyathea species. Gallic acid was present only in C. crinita with the $R_{f}$ value 0.49 . The developed HPTLC profiles can be used for identification and quantitative determination of phenolics, flavonoids, and tannins. This method is also suitable for rapid screening of Cyathea species for chemotypic assessment and also for quality control purposes.
\end{abstract}

\section{Introduction}

Plants synthesize a wide variety of chemical compounds which can be sorted by their chemical class, biosynthetic origin, and functional groups. The medicinal value of plants lies in chemical substances or group of compounds that produce a definite physiological action in the human body [1]. The active ingredients present in medicinal plants can be used for therapeutic purposes and are precursors of chemotherapeutical semisynthesis [2]. The beneficial effects of plants are usually due to the secondary metabolites which provide temporary relief to symptomatic problems, health promoting characteristics, and curative properties. Plant phenolic compounds include flavonoids, tannins, glycosides, coumarins, anthraquinones, lignans, and lignins. They may act as phytoalexins, antifeedants, and attractants for pollinators. In addition, they act as contributors to the plant pigmentation [3]. With the advent of modern scientific methods, medicinal plants came under chemical scrutiny, leading to the isolation of the active principles. Soon after their isolation and characterization, these compounds either in pure state or in the form of well-characterized extracts became part of pharmacopoeias of several countries.
According to draft guidelines stated by the USFDA, a marker compound is a chemical constituent of a botanical raw material that is used for identification or quality control purposes, especially when the active constituents are not identified. The active constituent is responsible for the intended pharmacological activity or therapeutic effects. Chemical standardization often involves chemical identification by spectroscopic or chromatographic fingerprint and chemical assay for active constituents or marker compounds if available. The analytical methods developed can be used for chemical fingerprinting and assaying of marker or active compounds [4]. Chemical fingerprints obtained by chromatographic techniques are strongly recommended for the purpose of quality control of herbal medicines, since they might represent appropriately the chemical integrity of the herbal medicines and its products are therefore used for authentication and identification of the plant [5].

Tree ferns are usually considered under a single family Cyatheaceae except Holttum [6] who suggested a polyphyletic derivation with four families. It is one of the most interesting families among the pteridophytes due to their striking morphology and wide geographical distribution with diversity centers in the tropics, subtropics, and southern 
temperate regions. They are considered as primitive, though they represent different lines of evolution. These ferns display great ecological conservatism as most species are terrestrial plants of moist forests and are intolerant to longer periods of drought or frost. Furthermore, they show a greater provincialism and endemism than most fern groups [7]. With the traditional healing system that is actively searching and expanding its pharmacopoeia in order to treat a large number of complaints, an environment with great floral diversity is slipping away unlearned by a new generation of healers. The scientific and traditional communities need a resource where data on the phytochemical aspects of these ferns are collated. Hence, the present study was intended to study the HPTLC fingerprint profile (phenolics, flavonoids, and tannins) of Cyathea nilgirensis Holttum, Cyathea gigantea (Wall. ex. Hook.) Holttum, and Cyathea crinita (Hook.) Copel.

\section{Materials and Methods}

2.1. Collection of Plant Materials. Specimens for the present study were collected from various natural habitats of Tamil Nadu. C. nilgirensis were harvested in and around Kakkachi stream $(1,725 \mathrm{~m})$, Kothayar, Tirunelveli Hills $\left(8^{\circ} 44^{\prime} \mathrm{N}\right.$ and $\left.77^{\circ} 44^{\prime} \mathrm{E}\right)$, C. gigantea from the roadsides near Nadugani $(2,637 \mathrm{~m})$, Nilgiris Hills $\left(11^{\circ} 24^{\prime} \mathrm{N}\right.$ and $\left.76^{\circ} 44^{\prime} \mathrm{E}\right)$, and C. crinita from the Anglade Institute of Natural History, Shenbaganur, Kodaikanal $(2,195 \mathrm{~m})$, Palni Hills $\left(10^{\circ} 13^{\prime} \mathrm{N}\right.$ and $\left.77^{\circ} 32^{\prime} \mathrm{E}\right)$, Western Ghats, South India. The plants were identified based on the Pteridophyte Flora of the Western Ghats, South India by Manickam and Irudayaraj [8]. Herbarium specimens were prepared and the voucher specimens were deposited in the St. Xavier's College Herbarium (XCH), Palayamkottai, Tamil Nadu, India, for further reference (C. nilgirensis, XCH 25423; C. gigantea, XCH 25422; and C. crinita, XCH 25424).

2.2. Preparation of Extracts. The collected species of Cyathea were thoroughly washed with tap water followed by distilled water. They were blotted on the blotting paper and shade dried at room temperature in the dark. The shade dried plant samples were ground to fine powder using mechanical grinder. $30 \mathrm{~g}$ powdered samples were extracted successively with $180 \mathrm{~mL}$ of ethanol using Soxhlet extractor for $8-12 \mathrm{~h}$ at a temperature not exceeding the boiling point. The extracts were concentrated in a vacuum at $40^{\circ} \mathrm{C}$ using rotary evaporator.

2.3. HPTLC Analysis. HPTLC studies were carried out using the standard method described by Wagner et al. [9]. $25 \mathrm{mg}$ of ethanolic extracts of selected Cyathea species was weighed accurately in an electronic balance (Shimadzu). It was dissolved in $0.5 \mathrm{~mL}$ of ethanol and centrifuged at $3000 \mathrm{rpm}$ for $5 \mathrm{~min}$. These solutions were used as test solution for phenolics, flavonoids, and tannins. $2 \mu \mathrm{L}$ of test solutions and $2 \mu \mathrm{L}$ of standard solution were loaded as $5 \mathrm{~mm}$ band length in the silica gel $60 \mathrm{~F}_{254}$ TLC plate using Hamilton syringe and CAMAG Linomat 5 instrument. The samples loaded plate was kept in TLC twin trough developing
TABLE 1: HPTLC: phenolics profile of studied Cyathea species.

\begin{tabular}{|c|c|c|c|c|}
\hline $\begin{array}{l}R_{f} \\
\text { values }\end{array}$ & C. nilgirensis & C. gigantea & C. crinita & Assigned substance \\
\hline 0.05 & + & + & + & Phenolic 2 \\
\hline 0.26 & & + & + & Phenolic 4 \\
\hline 0.28 & + & & & Catechin \\
\hline 0.32 & + & + & + & Unknown \\
\hline 0.43 & + & + & + & Phenolic 5 \\
\hline 0.49 & & & + & Phenolic 6 \\
\hline 0.55 & + & & + & Unknown \\
\hline 0.59 & & & + & Phenolic 7 \\
\hline 0.66 & & + & & Unknown \\
\hline 0.72 & & & + & Phenolic 8 \\
\hline 0.75 & + & + & + & Quercetin \\
\hline 0.80 & + & & & Unknown \\
\hline 0.83 & + & + & + & Unknown \\
\hline 0.92 & & + & + & Unknown \\
\hline
\end{tabular}

chamber (after being saturated with solvent vapour) with respective mobile phases, namely, toluene-acetone-formic acid $(4.5: 4.5: 1)$ for phenolics, toluene-acetone-formic acid $(4.5: 4.5: 1)$ for flavonoids, and toluene-ethyl acetate-formic acid-methanol $(3: 3: 0.8: 0.2)$ for tannins. The plate was developed up to $90 \mathrm{~mm}$.

The developed plate was dried by hot air to evaporate solvents from the plate. The plate was kept in photodocumentation chamber and the images were captured under visible light, UV $254 \mathrm{~nm}$, and UV $366 \mathrm{~nm}$. The developed plate was sprayed with respective spraying reagents, namely, FolinCiocalteu reagent for phenolics, $1 \%$ ethanolic aluminium chloride reagent for flavonoids, and $5 \%$ ferric chloride reagent for tannins. The plates were dried at $100^{\circ} \mathrm{C}$ in hot air oven. The plate was photodocumented in visible light and UV $366 \mathrm{~nm}$ mode using photodocumentation chamber. Before derivatization, the plate was fixed in scanner stage and scanned at UV $254 \mathrm{~nm}$ and UV $366 \mathrm{~nm}$. After derivatization, the plate was fixed in scanner stage and scanned at UV $366 \mathrm{~nm}$. The peak table, peak display, and peak densitogram were noted. The software used was winCATS 1.3.4 version.

\section{Results}

3.1. Phenolics Profile. HPTLC separation of phenolics determined high resolution and reproducible peaks in the studied Cyathea species. The results determined the presence of 27 different types of phenolics bands and validated 14 different $R_{f}$ values ranged from 0.05 to 0.92 (Figure 1; Table 1). The maximum number (11) of phenolics has been observed in the ethanolic extract of $C$. crinita. Among the different types of phenolics, the bands with $R_{f}$ values $0.05,0.32,0.43,0.75$, and 0.83 demonstrated their presence in all the three studied species of Cyathea. The phenolic band with $R_{f}$ value 0.75 confirmed the presence of quercetin in the ethanolic extract of all the three studied Cyathea species. The percentage of quercetin presence was as follows: C. nilgirensis (0.19), C. 


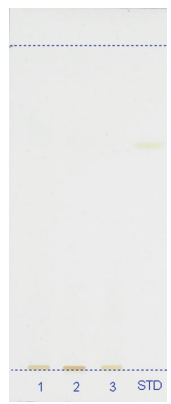

(a)

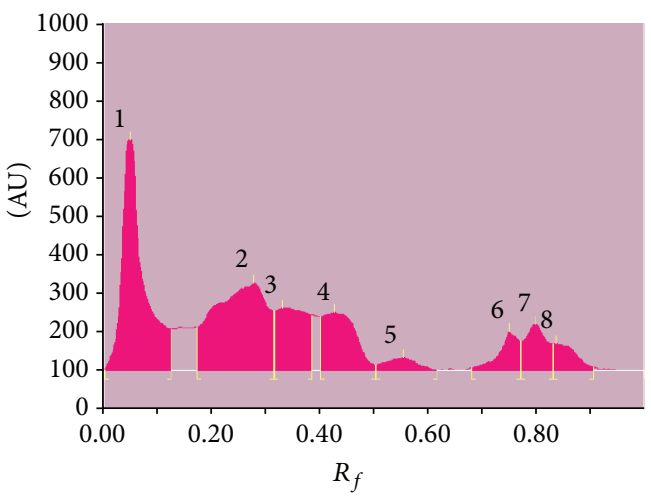

(f)

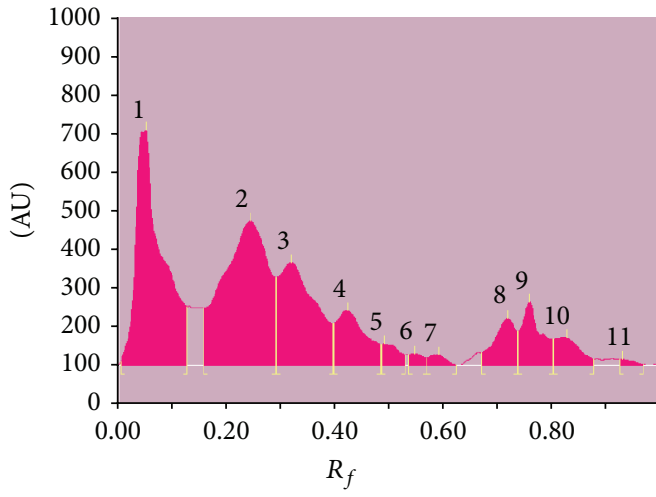

(h)

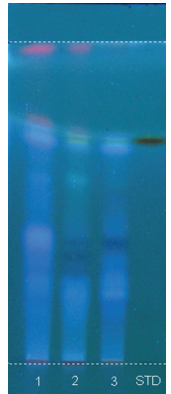

(b)

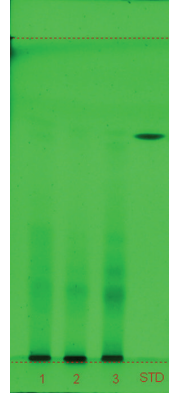

(c)

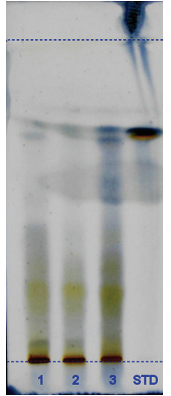

(d)

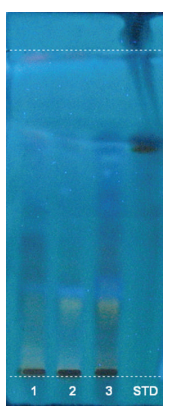

(e)

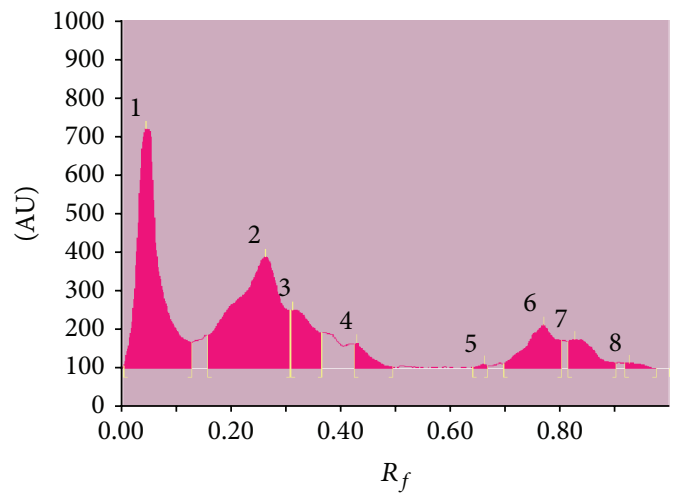

(g)

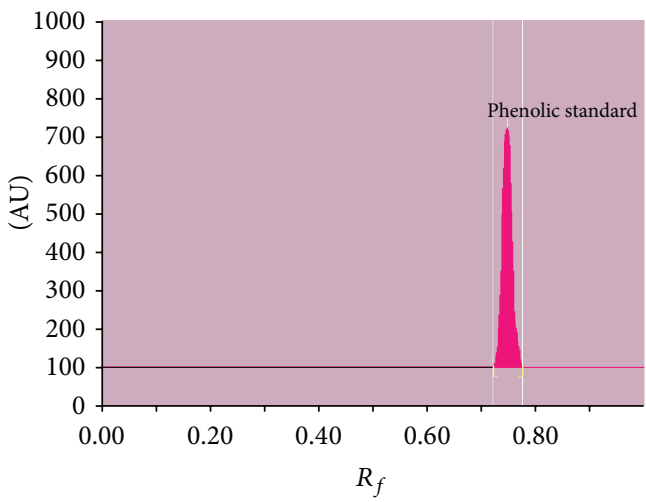

(i)

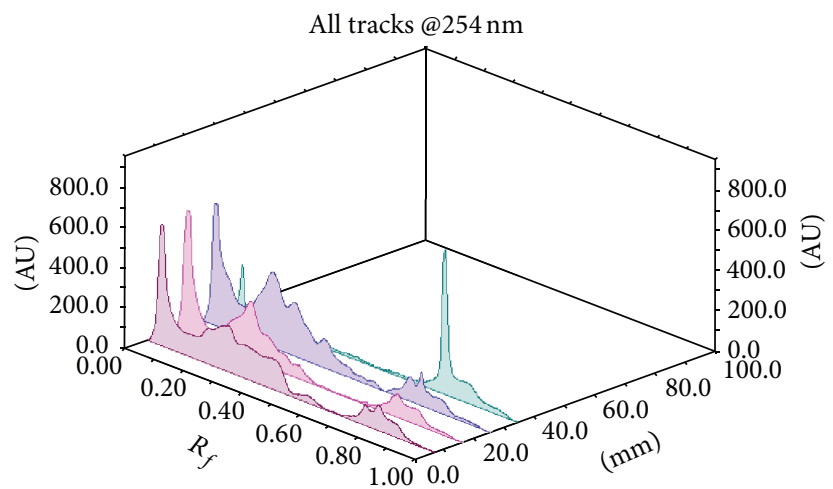

(j)

FIgURE 1: HPTLC (chromatogram). Phenolics profile of Cyathea species. (a-c) Before derivatization ((a) visible light; (b) UV light, $366 \mathrm{~nm}$; (c) UV light, $254 \mathrm{~nm}$ ). (d and e) After derivatization ((d) visible light; (e) UV light, $366 \mathrm{~nm}$ ); (f) peak densitogram of C. nilgirensis; (g) peak densitogram of C. gigantea; (h) peak densitogram of C. crinita; (i) standard phenolic-quercetin; (j) 3D display of all tracks. 
gigantea (0.32), and C. crinita (0.30). HPLC analysis validated the quercetin occurrence in the ethanolic extracts of Cyathea species with the retention times, namely, RT $17.39 \mathrm{~min}$ in $C$. gigantea, RT $18.09 \mathrm{~min}$ in C. nilgirensis, and RT $16.06 \mathrm{~min}$ in C. crinita. The band with $R_{f}$ value 0.28 validated the presence of catechin in C. nilgirensis. The phenolic bands with $R_{f}$ values 0.28 and 0.80 showed their unique presence in $C$. nilgirensis whereas the bands 0.26 and 0.66 displayed their occurrence only in C. gigantea. The bands with $R_{f}$ values 0.49 , 0.59 , and 0.72 expressed their existence only in C. crinita.

3.2. Flavonoids Profile. Ethanolic extracts of studied Cyathea species represented the presence of 28 bands and substantiated 13 types of flavonoids with $R_{f}$ values ranged from 0.05 to 0.82 (Figure 2; Table 2). The maximum number (10) of flavonoids was illustrated in C. crinita followed by $C$. nilgirensis and C. gigantea (9). Flavonoids with $R_{f}$ values 0.05 , $0.23,0.30,0.43$, and 0.73 showed their presence in the three studied species of Cyathea. C. nilgirensis showed the presence of distinct band with $R_{f}$ value 0.77 . The flavonoid bands with $R_{f}$ values 0.14 and 0.71 displayed their unique presence in $C$. crinita. The flavonoid with $R_{f}$ value 0.18 confirmed the presence of rutin in $C$. gigantea. The HPLC analysis confirmed the rutin existence in the ethanolic extract of $C$. gigantea with RT 19.24 min. Rutin was failed to observe in the other two studied Cyathea species.

3.3. Tannins Profile. Mobile phases of different compositions were tested in Cyathea species in order to obtain high resolution and reproducible peaks. The results showed the presence of 30 bands and validated 17 diverse types of tannins with $R_{f}$ values ranged from 0.05 to 0.93 (Figure 3; Table 3). The maximum number (13) of tannins was found in C. crinita when compared to the other studied species. C. nilgirensis showed 10 different tannins and C. gigantea demonstrated the presence of 8 different tannins. Among the different types, tannin with the $R_{f}$ values $0.05,0.09$, and 0.82 showed their presence in all the three studied Cyathea species. The tannin bands $0.24,0.34,0.66$, and 0.73 showed their unique presence in C. nilgirensis. C. crinita expressed three distinct bands, namely, $0.49,0.56$, and 0.93 . Gallic acid was present only in C. crinita $(0.09 \%)$ with the $R_{f}$ value 0.49 .

\section{Discussion}

Chromatography is the lynchpin of phytochemistry and is the key to obtain pure compounds for development into therapeuticals. Separation, identification, and structure elucidation of biologically active compounds have been facilitated by continual development of chromatographic methods. They also play a fundamental role as an analytical technique for quality control and standardization of phytotherapeuticals. Generally, two approaches being used for standardization are fingerprint analysis by HPTLC/HPLC and quantification of individual chemical markers [10]. It ensures reproducible pharmaceutical quality of herbal products. Characteristic HPTLC fingerprinting of particular plant species will not
TABLE 2: HPTLC: flavonoids profile of studied Cyathea species.

\begin{tabular}{|c|c|c|c|c|}
\hline $\begin{array}{l}R_{f} \\
\text { values }\end{array}$ & C. nilgirensis & C. gigantea & C. crinita & Assigned substance \\
\hline 0.05 & + & + & + & Unknown \\
\hline 0.14 & & & + & Flavonoid 1 \\
\hline 0.18 & & + & & Rutin \\
\hline 0.23 & + & + & + & Flavonoid 2 \\
\hline 0.30 & + & + & + & Flavonoid 3 \\
\hline 0.36 & + & + & & Flavonoid 4 \\
\hline 0.43 & + & + & + & Unknown \\
\hline 0.49 & & + & + & Unknown \\
\hline 0.60 & & + & + & Flavonoid 5 \\
\hline 0.68 & + & + & & Flavonoid 6 \\
\hline 0.71 & & & + & Unknown \\
\hline 0.73 & + & + & + & Unknown \\
\hline 0.77 & + & & & Unknown \\
\hline 0.82 & + & & + & Unknown \\
\hline
\end{tabular}

only help in identification of that species but also provide basic information useful for the isolation, purification, and characterization of marker chemical compounds of the species [11]. It is useful as a phytochemical marker and also a good estimator of genetic variability in plant populations. The presence or absence of chemical constituent has been found useful in the placement of the plant in taxonomic categories. HPTLC profile differentiation is an important procedure [12] which produces visible chromatograms and complex information about the entire sample. It also provides visualization of the separated constituents and online identification of the analyte by in situ spectrum scanning and postchromatographic derivatization, along with $R_{f}$ comparison with the standard [13]. HPTLC method can be used for phytochemical profiling and quantification of compounds present in plant samples.

With the increasing demand for natural products as medicines, there is an urgent need for standardization of plant products. Chromatographic fingerprint is a rational option to meet the need for more effective and powerful quality assessment to traditional system of medicine throughout the world [14]. The optimized chromatographic fingerprint is not only an alternative analytical tool for authentication, but also an approach to express the various patterns of chemical ingredients distributed in the plant material and to preserve such "database" for further sustainable studies [15]. HPTLC results on ethanolic extracts of C. nilgirensis, C. gigantea, and C. crinita provided an impressive result directed towards the presence of diverse type of phytochemicals (phenolics, flavonoids, and tannins). The selection of appropriate solvent system for a particular plant extract can be achieved only by analyzing the $R_{f}$ values of compounds in different solvent system. The variation in $R_{f}$ values of the phytochemicals provides an important clue about selection of appropriate solvent system for separation of pure compounds by column chromatography. Mixture of solvents with variable polarity in different ratio can be used for separation of 


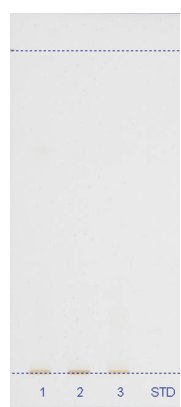

(a)

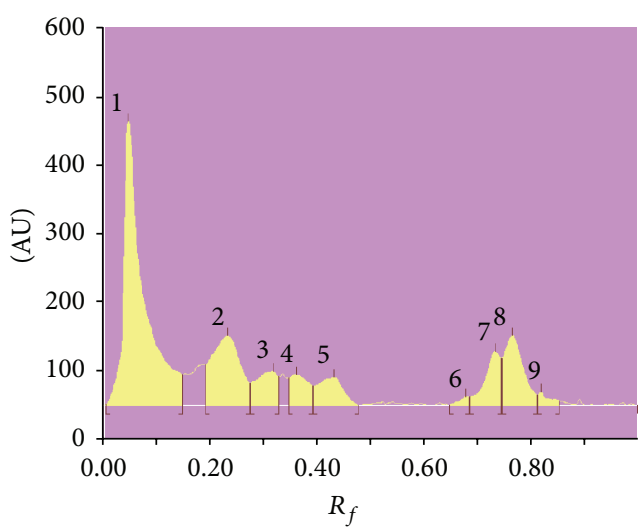

(f)

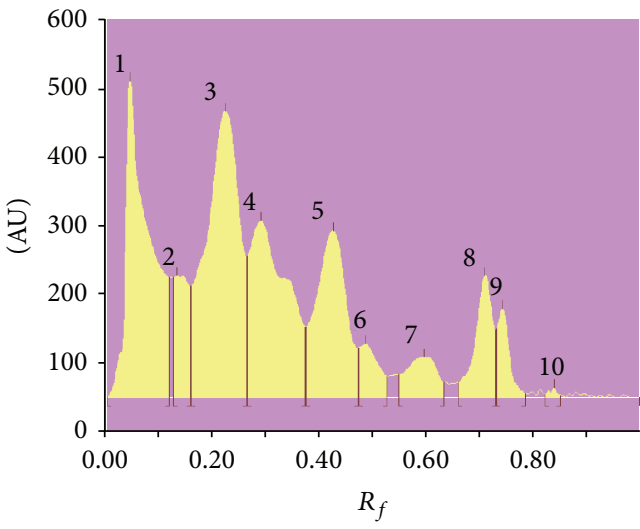

(h)

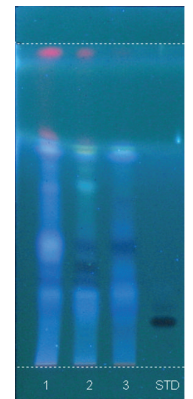

(b)

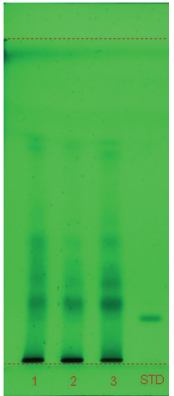

(c)

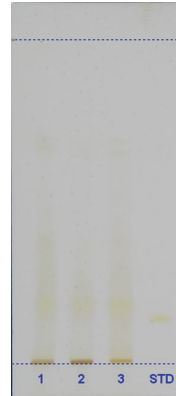

(d)

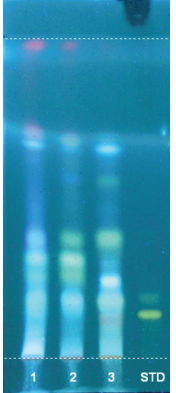

(e)

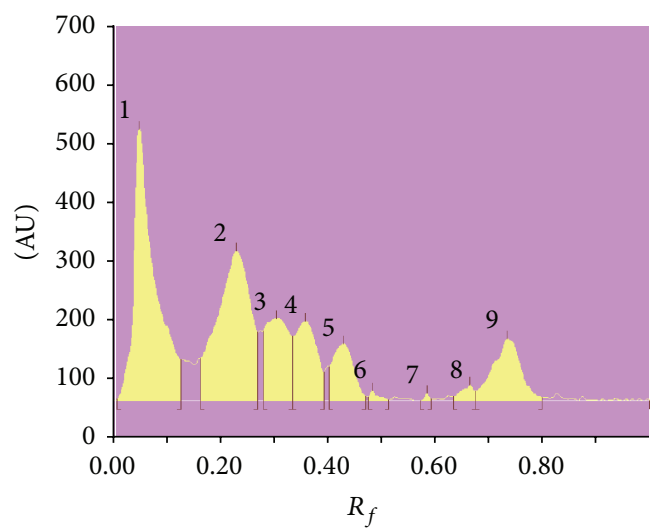

(g)

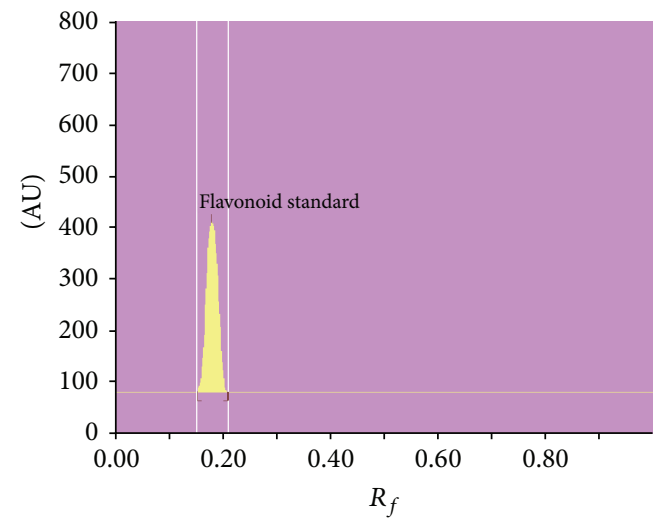

(i)

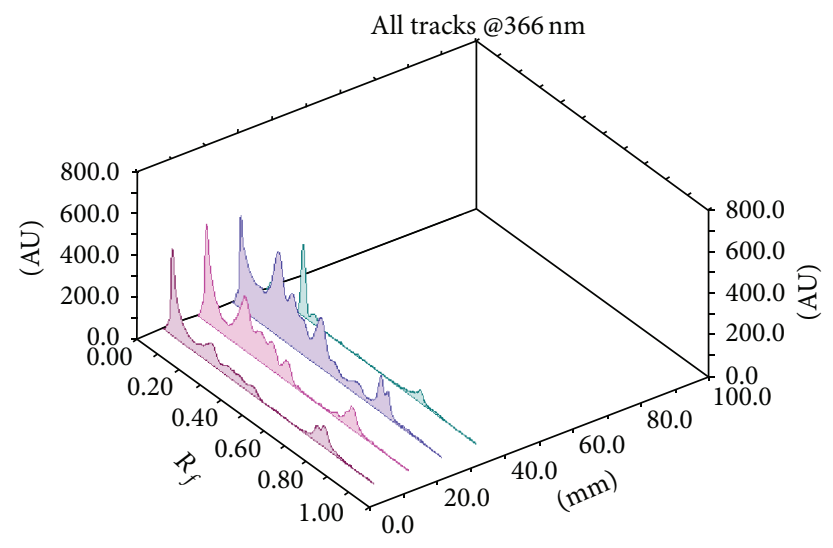

(j)

FIGURE 2: HPTLC (chromatogram). Flavonoids profile of Cyathea species. (a-c) Before derivatization ((a) visible light; (b) UV light, $366 \mathrm{~nm}$; (c) UV light, $254 \mathrm{~nm}$ ). (d and e) After derivatization ((d) visible light; (e) UV light, $366 \mathrm{~nm}$ ); (f) peak densitogram of C. nilgirensis; (g) peak densitogram of C. gigantea; (h) peak densitogram of C. crinita; (i) standard flavonoid-rutin; (j) 3D display of all tracks. 


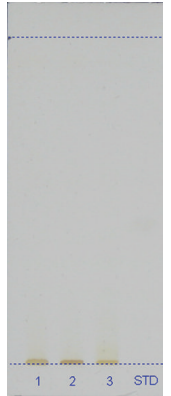

(a)

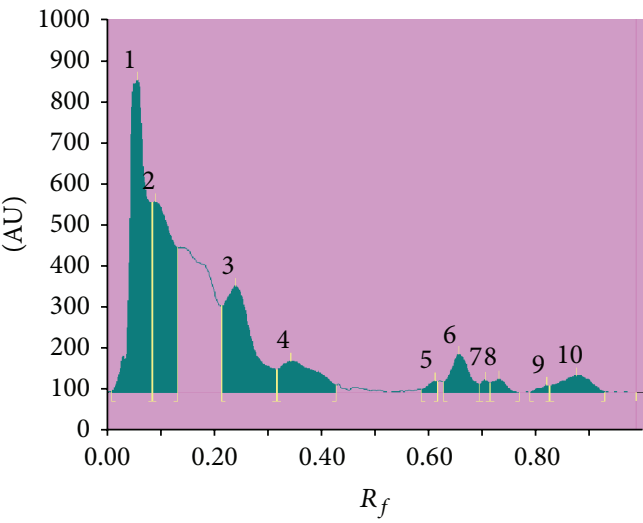

(e)

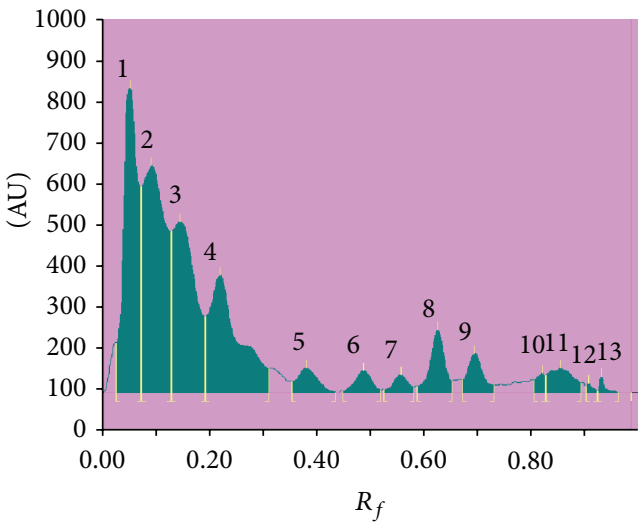

(g)

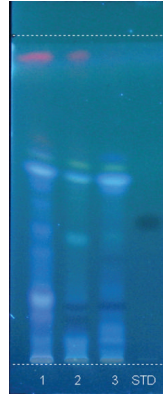

(b)

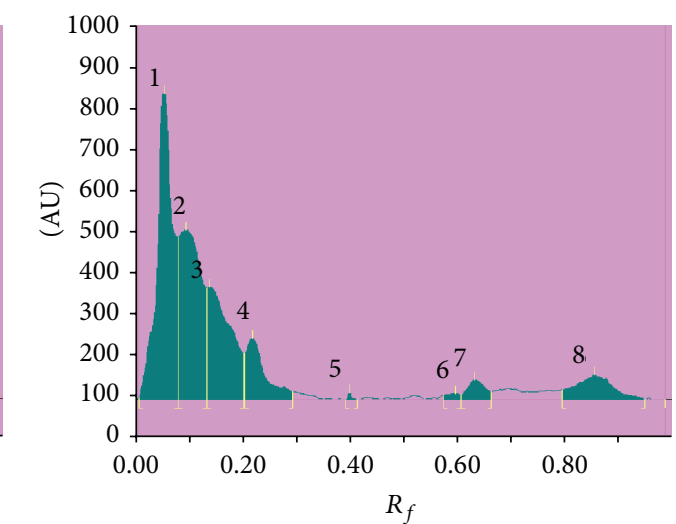

(f)

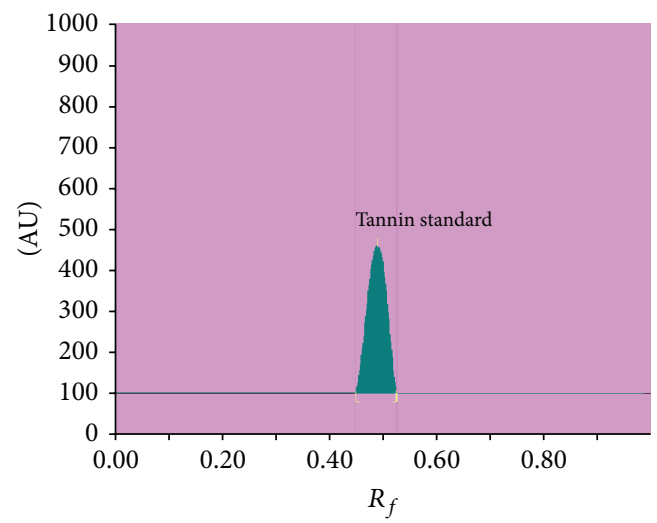

(h)

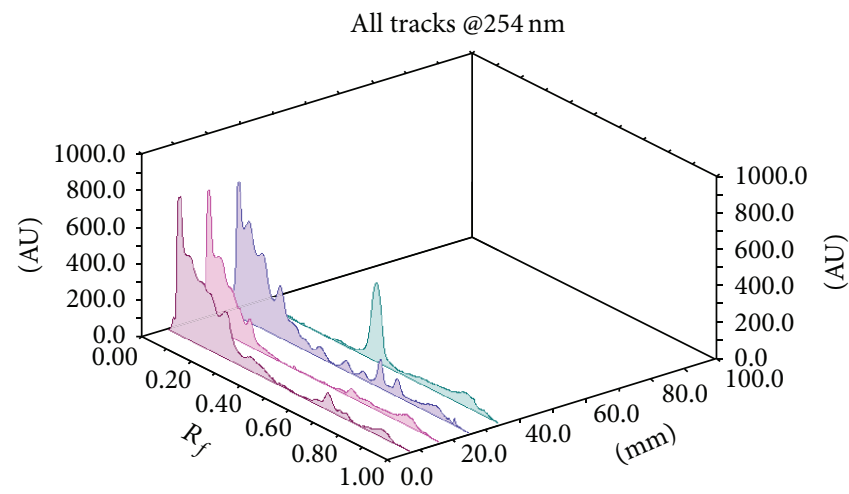

(i)

FIgURE 3: HPTLC (chromatogram). Tannins profile of Cyathea species. (a-c) Before derivatization ((a) visible light; (b) UV light, $366 \mathrm{~nm}$; (c) UV light, $254 \mathrm{~nm}$ ). (d) After derivatization (visible light); (e) peak densitogram of C. nilgirensis; (f) peak densitogram of C. gigantea; (g) peak densitogram of C. crinita; (h) standard tannin-gallic acid; (i) 3D display of all tracks. 
TABLE 3: HPTLC: tannins profile of studied Cyathea species.

\begin{tabular}{|c|c|c|c|c|}
\hline $\begin{array}{l}R_{f} \\
\text { values }\end{array}$ & C. nilgirensis & C. gigantea & C. crinita & Assigned substance \\
\hline 0.05 & + & + & + & Tannin 1 \\
\hline 0.09 & + & + & + & Tannin 2 \\
\hline 0.15 & & + & + & Unknown \\
\hline 0.22 & & + & + & Tannin 3 \\
\hline 0.24 & + & & & Unknown \\
\hline 0.34 & + & & & Unknown \\
\hline 0.40 & & + & + & Unknown \\
\hline 0.49 & & & + & Gallic acid \\
\hline 0.56 & & & + & Tannin 4 \\
\hline 0.60 & + & + & & Unknown \\
\hline 0.63 & & + & + & Unknown \\
\hline 0.66 & + & & & Unknown \\
\hline 0.69 & + & & + & Unknown \\
\hline 0.73 & + & & & Unknown \\
\hline 0.82 & + & + & + & Unknown \\
\hline 0.88 & + & & + & Unknown \\
\hline 0.93 & & & + & Unknown \\
\hline
\end{tabular}

pure compound from plant extracts. The HPLC analysis confirmed the presence of quercetin and rutin in the ethanolic extracts of Cyathea species. The results of the present study directly coincided with the previous observations [16, 17]. The developed HPTLC method will provide sufficient information about therapeutic efficacy of the drug and also in the identification, standardization, and quality control of studied Cyathea species.

\section{Conclusion}

The results of the present study revealed a better separation of individual secondary metabolites and further facilitate their quantitative estimation and qualitative separation of pharmacologically active chemical compounds.

\section{Conflict of Interests}

The authors declare that they have no conflict of interests.

\section{References}

[1] H. O. Edeoga, D. E. Okwu, and B. O. Mbaebie, "Phytochemical constituents of some Nigerian medicinal plants," African Journal of Biotechnology, vol. 4, no. 7, pp. 685-688, 2005.

[2] WHO, The Selection of Essential Drugs, Second Report of the WHO Expert Committee, vol. 641 of WHO Technical Report Series, World Health Organization, Geneva, Switzerland, 1979.

[3] F. Shahidi and M. Naczk, Phenolics in Food and Nutraceuticals: Sources, Applications and Health Effects, CRC Press, Boca Raton, Fla, USA, 2004.

[4] E. S. Ong, "Extraction methods and chemical standardization of botanicals and herbal preparations," Journal of Chromatography $B$, vol. 812, no. 1-2, pp. 23-33, 2004.
[5] N. A. Farooqui, A. Dey, G. N. Singh, T. S. Easwari, and M. K. Pandey, "Analytical techniques in quality evaluation of herbal drugs," Asian Journal of Pharmaceutical Research, vol. 4, no. 3, pp. 112-117, 2014.

[6] R. E. Holttum, "Posing the problems," in The Phylogeny and Classification of the Ferns, A. C. Jermy, J. A. Crabbe, and B. A. Thomas, Eds., Supplement no. 1 to the Botanical Journal of the Linnean Society, vol. 67, pp. 1-284, Linnean Society of London, London, UK, 1973.

[7] R. M. Tryon and G. J. Gastony, “The biogeography of endemism in the Cyatheaceae," Fern Gazette, vol. 11, pp. 73-79, 1975.

[8] V. S. Manickam and V. Irudayaraj, Pteridophyte Flora of the Western Ghats, South India, BI Publications Private Limited, New Delhi, India, 1992.

[9] H. Wagner, S. Baldt, and E. M. Zgainski, Plant Drug Analysis, Springer, Berlin, Germany, 1996.

[10] M. B. Patel and S. H. Mishra, "Quantitative analysis of marker constituent swertisin in Enicostemma hyssopifolium verdoon by RP-HPLC and HPTLC," Acta Chromatographica, vol. 24, no. 1, pp. 85-95, 2012.

[11] D. Yadav, N. Tiwari, and M. M. Gupta, "Simultaneous quantification of diterpenoids in Premna integrifolia using a validated HPTLC method," Journal of Separation Science, vol. 34, no. 3, pp. 286-291, 2011.

[12] D. S. S. Kpoviéssi, F. Gbaguidi, J. Gbénou et al., "Validation of a method for the determination of sterols and triterpenes in the aerial part of Justicia anselliana (Nees) T. Anders by capillary gas chromatography," Journal of Pharmaceutical and Biomedical Analysis, vol. 48, no. 4, pp. 1127-1135, 2008.

[13] Md. Faiyazuddin, A. Rauf, N. Ahmad et al., "A validated HPTLC method for determination of terbutaline sulfate in biological samples: application to pharmacokinetic study," Saudi Pharmaceutical Journal, vol. 19, no. 3, pp. 185-191, 2011.

[14] L. P. Haliński, J. Szafranek, B. M. Szafranek, M. Gołębiowski, and P. Stepnowski, "Chromatographic fractionation and analysis of the main components of eggplant (Solanum melongena L.) leaf cuticular waxes," Acta Chromatographica, vol. 21, no. 1, pp. 127-137, 2009.

[15] S. Tiwari, U. Bhadoriya, L. Saini, A. Gupta, and S. Solanki, "Quantitative analysis of glycyrrhizic acid by HPTLC in herbal formulation," Asian Journal of Pharmacy \& Life Science, vol. 1, no. 2, pp. 124-127, 2011.

[16] G. Toker, S. Turkoz, and N. Erdemoglu, "High performance liquid chromatographic analysis of rutin in some Turkish plants II," Journal of Chemical Society of Pakistan, vol. 20, no. 4, pp. 240-243, 1998.

[17] G. Mradu, S. Saumyakanti, M. Sohini, and M. Arup, "HPLC profiles of standard phenolics compounds present in medicinal plants," International Journal of Pharmacognosy and Phytochemical Research, vol. 4, no. 3, pp. 162-167, 2012. 

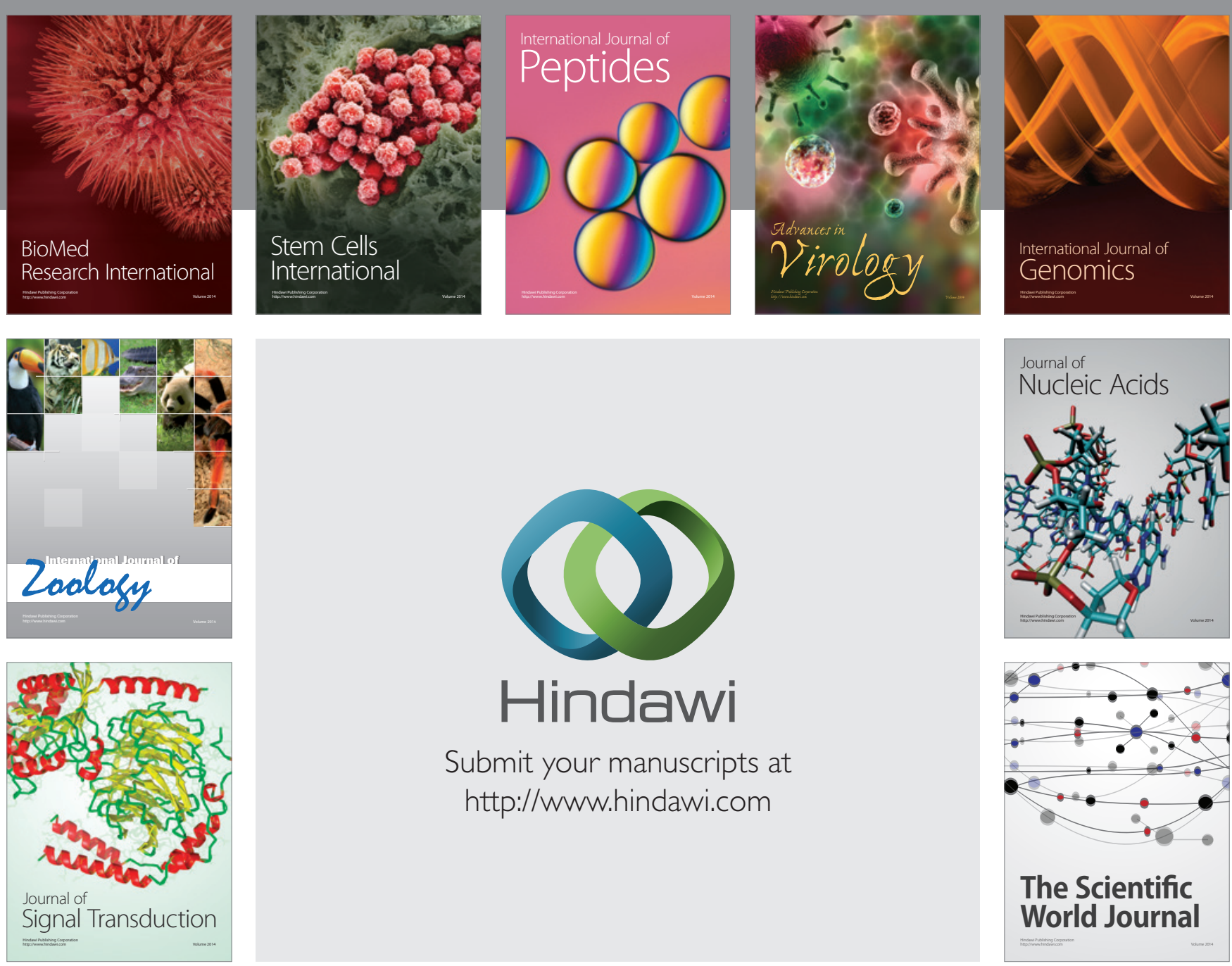

Submit your manuscripts at

http://www.hindawi.com
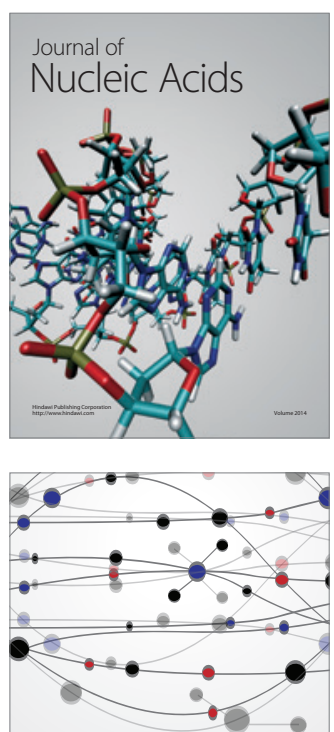

The Scientific World Journal
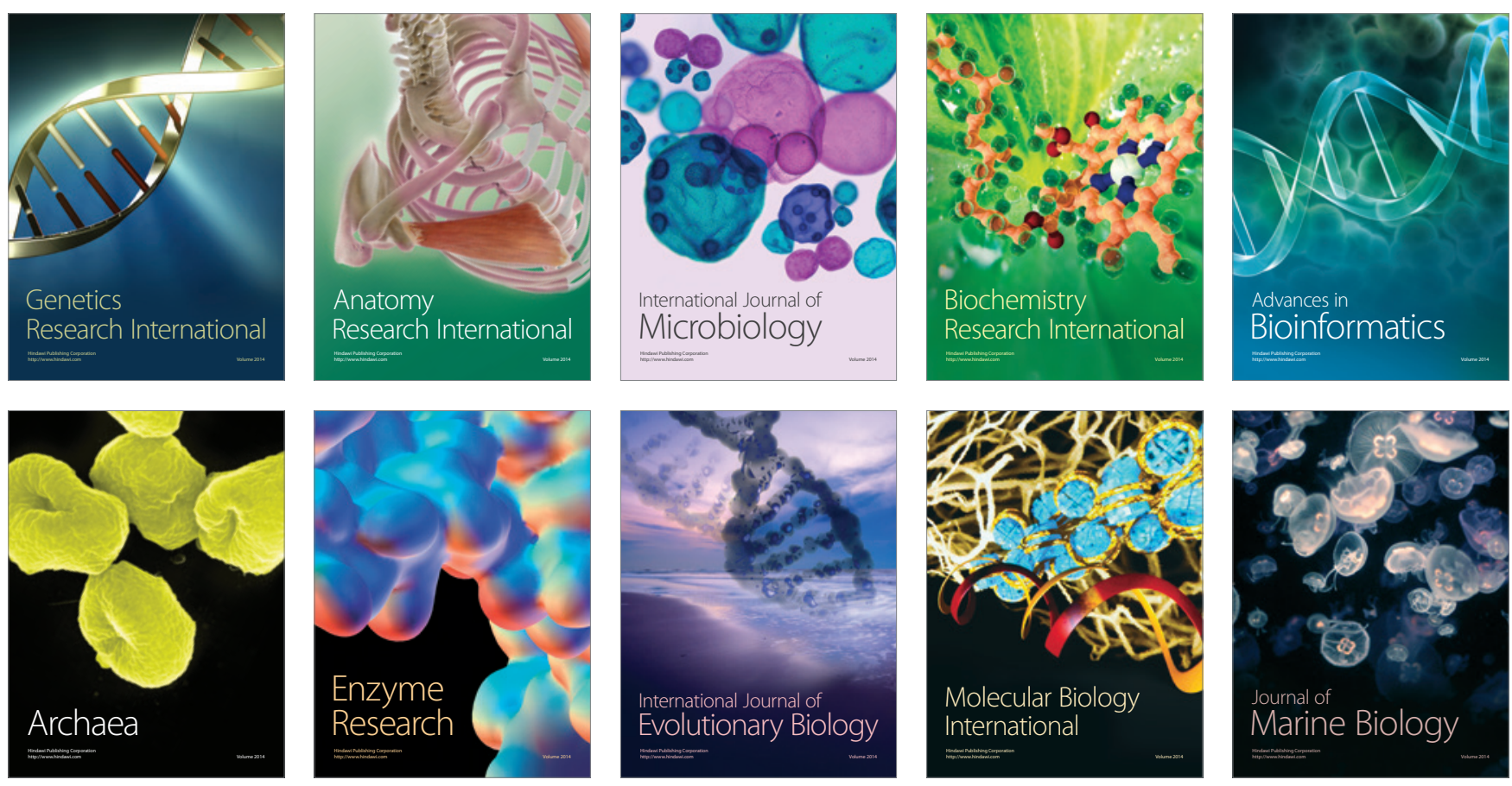